\title{
An agile high-frequency radar used for ionospheric research
}

\author{
Jingye Yan $^{1,2}$, Ailan Lan ${ }^{1,2, *}$, Xiang Deng ${ }^{1,2,3}$, Jiaojiao Zhang ${ }^{1,2}$, Chi \\ ${ }^{1}$ National Space Science Center, Chinese Academy of Sciences, Beijing 100190, China \\ 2 State Key Laboratory of Space Weather, Beijing 100190, China \\ ${ }^{3}$ University of Chinese Academy of Sciences, Beijing, 100049, China \\ ${ }^{4}$ Jiamusi University, Jiamusi 154007, China
}

Received 30 May 2020 / Accepted 3 March 2021

\begin{abstract}
The Super Dual Radar Network (SuperDARN) is an ernational high-frequency (HF) radar network used to study plasma convection in the upper atmosphere. A agile SuperDARN radar (AgileDARN radar) was deployed to join the network in Jianusi, hina. The Ag DARN radar is a digital phased array radar equipped with an field-programmable ate array (FPGA)-based digital processing unit (DPU). It can operate as a standard SuperDARN radar or a multiple intemultiple-out (MIMO) radar. Each channel can be controlled and processed separately. Digital bean forming (DBF) is used to make beam steering flexible and beam switching fast. Multiple b-beam fo ning for receiving can be implemented on FPGA or computer to improve position accuracy. Additionaly, internal calibration and external calibration are carried out to improve the perfor mance of beam forming. The internal calibration is a selfcalibration without any external connections. Calibration signals are produced by the generators in DPU. The gain and phase of transmitters/receivers are read compared to the based transmitter/receiver. Then the differences are recorded to comnensate for the onlances. During the external calibration, meteor trails are used as calibration sources to detect he imbal ce between antennas (including cables). The imbalances are compensated in the sane way a the intern calibration. By calibration, the amplitude and phase imbalances between channels are redoced significantly.
\end{abstract}

\section{Introduction}

The Super Dur Auroral Rar Network (SuperDARN) is an international collarat organization. The SuperDARN radars are high-frequency (HF) rada that operate on frequencies betwe 8 and $20 \mathrm{M}$. The radars are used to remotely sense the backsc ter from decameter-scale magnetic fieldalign plasma de sity irregularities in both the $\mathrm{E}$ and $\mathrm{F}$ regions of the iprospl re (Grcenwald et al., 1995). The movements of these irregulatities respond to energy coupled into the auroral and sub-auroral regions from the solar wind and magnetosphere. Therefore, Super ARN data provide scientists with information regarding the Earth's interaction with the space environment. It has been successful in addressing many space weather questions covering the area of ionospheric convection, field-aligned currents, magnetic reconnection, substorms, MHD waves, the neutral atmosphere, and so on (Chisham et al., 2007; Nishitani et al., 2019).

The history of SuperDARN has been introduced detailedly in some pieces of literature (Greenwald et al., 1995; Chisham

\footnotetext{
*Corresponding author: lanailan@nssc.ac. cn
}

et al., 2007; Nishitani et al., 2019). The extensive use of coherent scatter radars to study ionospheric convection began with the Scandinavian Twin Auroral Radar Experiment (STARE) in the late 1970s (Greenwald et al., 1978). STARE consists of two pulsed bistatic phased-array radars located in Nalvik, Norway and Hankasalmi, Finland. It was the only instrument capable of providing two-dimensional images of the structure of ionospheric convection patterns at that time. Subsequently, several paired VHF radar systems including the Sweden And Britain radar Experiment (SABRE) and the Bistatic Auroral Radar System (BARS) were developed. Both of these systems were identified as elements of the DARN network. However, the prototype for the current SuperDARN radar is Goose Bay HF radar developed by the Johns Hopkins University Applied Physics Laboratory, which commenced operations at Goose Bay in October 1983 (Greenwald et al., 1985). The initial purpose of the SuperDARN radar network was to observe the plasma convection at both Polar Regions; therefore, all the early SuperDARN radars covered the auroral and polar regions (Greenwald et al., 1995). However, during periods of magnetic storms and substorm expansions, radars at high-latitude were unable to completely map the convection process because the 
equatorward expansion of the auroral oval used to reach to midlatitude region. The expansion of the SuperDARN network to the mid-latitudes allows the SuperDARN network to trace the plasma convection processes during magnetic storm and substorm activity (Baker et al., 2007). The first mid-latitude radar, the Wallops Island radar, was constructed in 2005, shortly followed by the second mid-latitude radar in Hokkaido, Hokkaido East radar (HOK) in 2006. Until 2018, more than ten SuperDARN radars have been built in mid-latitude regions in the northern hemisphere (Nishitani et al., 2019).

There is another mid-latitude SuperDARN radar established in Jiamusi (China) in 2017. It is developed as an agile SuperDARN radar (AgileDARN) by the National Space Science Center, Chinese Academic of Sciences. The radar extends the coverage of the mid-latitude SuperDARN chain into China. Its data have been contributed to the SuperDARN data stream since 2019. The measurements during storm time show the contribution to the ionospheric convection patterns (Zhang et al., 2020). Supported by the Chinese Meridian Project-II, six additional AgileDARN radars in three sites (Bayinbluk, Siziwangqi Banner, and Longjing) are under construction to cover the mid-latitude region over China and expand the coverage of the mid-latitude HF radar considerably. The significantly expanded coverage of mid-latitude SuperDARN plays an important role in SAPS (sub-auroral polarization stream) research, including dependence of SPS on solar wind and geomagnetic drivers, interhemispheric comparisons of SAPS, evolution, and variability of SAPS, etc. (Nishitani et al., 2019). Meanwhile, the data from the mid-latitude radars a dramatic effect on the overall convection strength, increa the cross-polar cap potential and changing the potential conto on the nightside (Baker et al., 2007; Chisham er 2007).

The paper is organized as follows. In Section 2, we lescribe the system configuration and the specific design fecures in hardware. In Section 3, we focus on the a anced signal processing methods based on the distrib ed structur. We present the measured data to validate the pro oosed methods. Finally, the summary and conclusion are given Section 4.

\section{System description}

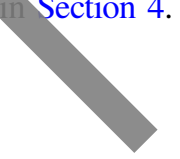

The AgileDARN dis built as one part of the SuperDARN nety ork. Its opc ional concept is essentially identical to other superD .RN radars. Meanwhile, the radar has some distine tive design

The Agile' ARN radar is composed of two arrays, 20 individua a sceivers, a digital processing unit (DPU), and a computer (shown as Fig. 1). The primary array consists of sixteen twin-tominated folded dipole (TTFD) elements with $12.8 \mathrm{~m}$ spacing, designed as the Blackstone radar (Sterne et al., 2011). The interferometric array with four antennas is used to estimate the elevation angle of the incoming signal. The phasing matrix used in the early SuperDARN radar is abandoned. Beam steering and beam switching are implemented by digital beam forming (DBF) (Whittington et al., 2002; Custovic et al., 2012; Deng et al., 2019). Each antenna has its own transceiver, which has a separate transmitter and receiver. The antennas are transmit-receive shared. They switch between the transmitters and receivers by transmitter/receiver $(\mathrm{Tx} / \mathrm{Rx})$ switches. Besides, directional couplers and combination switches are added in transceivers to implement internal calibration, see the "calibration circuit" subsection. All the control signals of the switches are provided by the DPU.

The DPU is composed of a direct digital synthesis (DDS) module, a digital signal processing module, a timing controller, 20 analog-to-digital converters (ADCs), and 20 digital-to-analog converters (DACs). It performs signal generation and processing, commanding and control of the system, instrument health monitoring, scientific data acquisition, and formatting. These functions are implemented based on fleld-progammable gate arrays (FPGAs), which makes the arar flexible. Most of the radar parameters are adjustable to meet differen ypes of observation. Each channel can be controlled and rocessed separately. Consequently, the radar can operate as multipleinput-multiple-output (MIMO) ralar, besices a standard SuperDARN radar. The wenty separate receivers are allowed each to be recorded and andepend ind Beamforming and calibrations $n$ be perforned online or offline as needed. The radar can tespond quickly to request for special observation. Therefe, the dar is called gileDARN.

The computer is used as a platform on which radar control software be run. The control software is to take control of the adar to operate as required. Operation parameters and secuences are configured in the software but carried out on the DPU. The to parts communicate with each other via a pe heral component interconnect express (PCIe) bus.

\subsection{Fiela or view}

The operating frequency of AgileDARN is between 8 and $20 \mathrm{MHz}$. The normalized spacing (in units of wavelength) varies with frequency. Therefore, the field of view (FOV) of the array becomes narrower with increasing frequency. In practice, HF propagation conditions mean that most ionospheric scatter is detected using frequencies in the range from 10 to $14 \mathrm{MHz}$ (Parkinson et al., 2006). The FOV is not less than $78^{\circ}$ at the frequency under $16 \mathrm{MHz}$. Above $16 \mathrm{MHz}$, grating sidelobes begin to appear for the outmost beams (Greenwald et al., 1985). The geographic coordinates of the radar site are $46.8^{\circ} \mathrm{N}, 130.5^{\circ} \mathrm{E}$. It looks to the northeast with a boresight azimuth of $44^{\circ}$ in geographic coordinates. The fields of view (FOV) of the AgileDARN radar (JME) along with the other Northern Hemisphere SuperDARN radars in operation are shown in Figure 2 (Zhang et al., 2020). According to the figure, we can see that the AgileDARN radar has a common viewing area with the Hokkaido pair of radars (HOK and HKW), which would provide a two-dimensional observation of ionospheric convection in this area. Moreover, the AgileDARN radar can be validated by comparing its observations with those from the Hokkaido radars (Zhang et al., 2020).

\subsection{Calibration circuit}

As mentioned, directional couplers and combination switches are used to perform internal calibration. Between antenna and $\mathrm{Tx} / \mathrm{Rx}$ switch, a low-loss directional coupler is inserted to sample a small amount of power for measurement. The coupler (shown in Fig. 3) has four ports, an input port (P1), a "through" port (P2), a coupled port (P3), and a reflected port $(\mathrm{P} 4)$. The coupler is a reciprocal device in that the coupled 


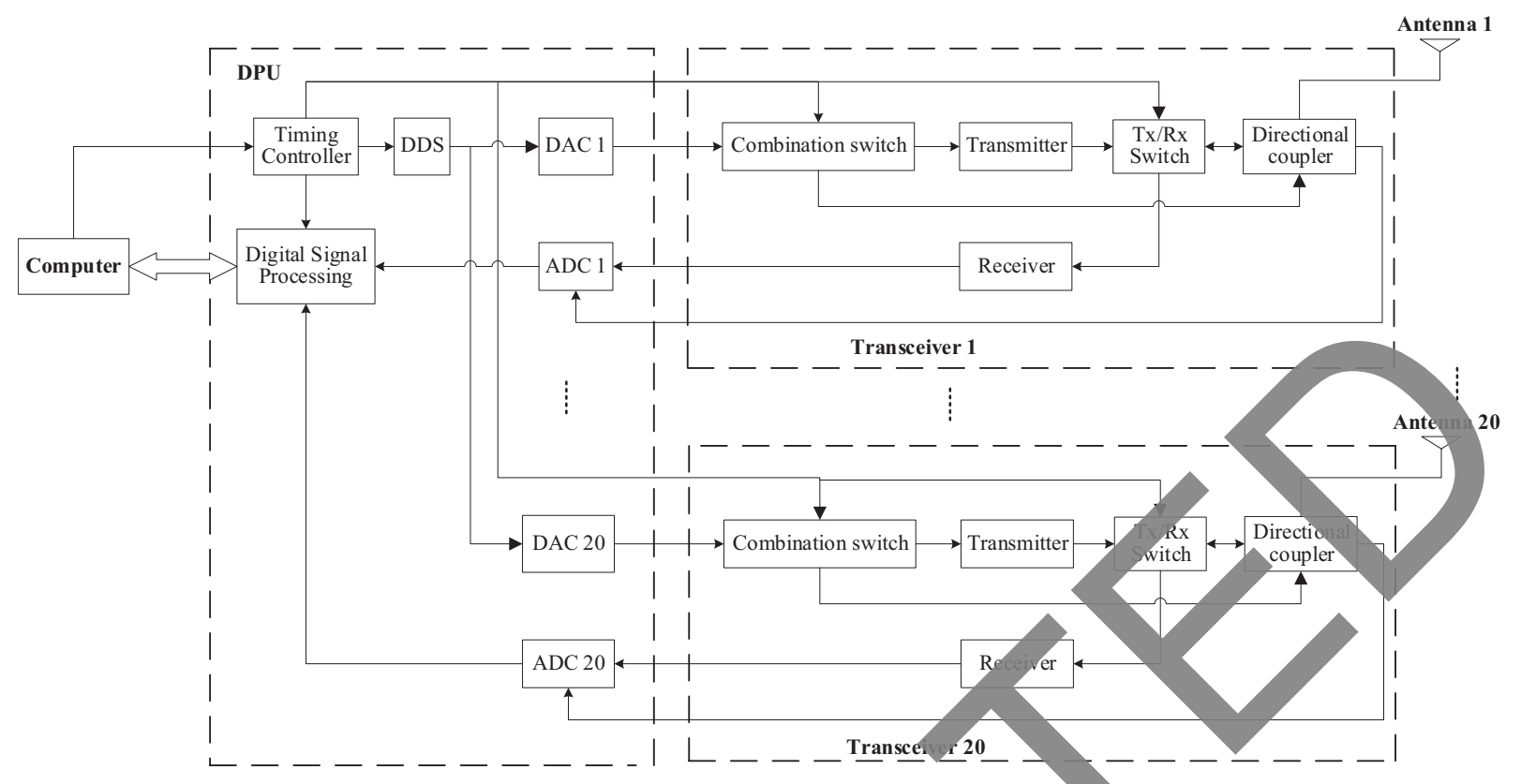

Figure 1. Simplified block diagram of the AgileDARN radar. It is composed of tho arrays with 20 antennas, 20 individual transceivers, a digital processing unit (DPU), and a computer.

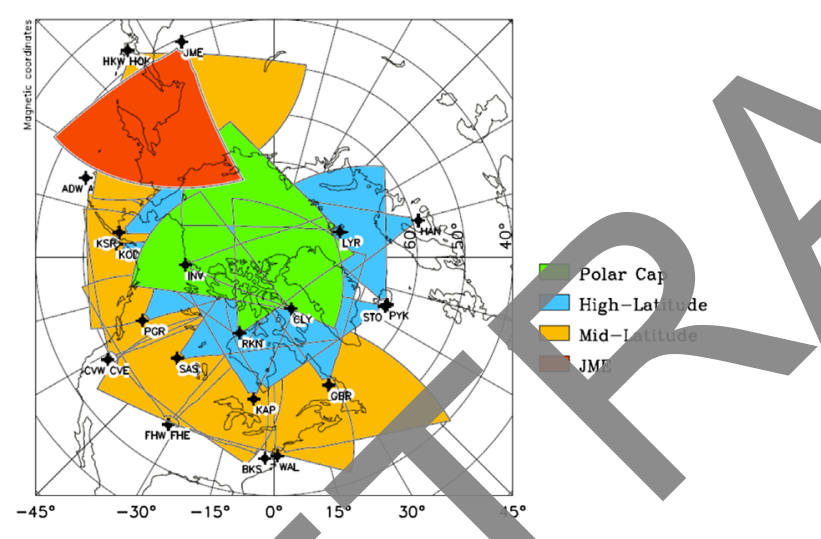

Figure 2. The FOV of the AgileDARN rada in the SuperDARN network. The FOV of the AgileDARN radar (JME) along with the other Northern Hen ohere Sy iDARN radars in operation. The FOV for the AgileDA ra is shaded red, and the FOVs for the other middle-1atitude, hig - titude, an polar cap radars are shaded yellow, $b^{1}$, and reen, respecti $y$. The FOVs are plotted in geomaonouc coord ates.

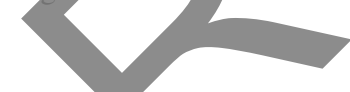

ports can be used to sample a portion of the mainline power, or they can be used to inject a signal into the main signal path. Besides, a directional coupler provides a sample port in both the forward and reverse directions. Based on the characteristics, directional couplers are used to implement internal calibration and voltage standing wave ratio (VSWR) detection in AgileDARN. A combination switch composed of three switches (S1, S2, and S3 in Figure 3) is added to carry out operation state switching control.

The operation states of AgileDARN include transmitting, receiving, transmitter calibrating, and receiver calibrating. Transmit signals and reference signals for calibrations are generated in DP . During ionosphere observation, transmit signals are amplified by transmitters then sent to antennas. Returns received are amplified and filtered in receivers to extract he desired signals. Transmitters and receivers are calibrated eparatey. The calibration scheme is shown in Figure 3. The signal paths of the transmitter and receiver calibration are presented as orange and blue, respectively. During transmitter calibration, the reference signal is sent to the transmitter and then enter the coupler. Most of the incident power is emitted by the antenna, and a fixed fraction of it is coupled on to P3 for transmitter calibration. When calibrating receivers, the P3 port is used as an input. The reference signal is injected into the coupler from P3. A sample of the incident signal is coupled on to $\mathrm{P} 1$ and fed to the receiver by $\mathrm{Tx} / \mathrm{Rx}$ switch. The signal passing through the receiver and $\mathrm{S} 1$ is converted to digital and processed in DPU.

\subsection{VSWR detection and protection circuit}

When AgileDARN operates in transmitting or transmitter calibration mode, the output power of a transmitter is up to 1000 watts. It is necessary to design a VSWR detection and protection circuit to protect amplifiers under severe mismatch. Directional couplers and dual log detectors are used in AgileDARN to detect VSWR (shown in Fig. 4; Rachakonda \& Hawkins, 2000). Once a signal is fed to P1, a sample of the incident and reflected signal are coupled to P3 and P4. The power from P4 is proportional to VSWR. The output of $\mathrm{P} 4$ is independent of the VSWR. They are fed to the dual log detector. The detector outputs the logarithmic subtraction of the two signals, which is proportional to the reflection coefficient. The voltage comparator triggers when the difference output $V_{\text {diff }}$ is more than the reference voltage $V_{\text {Ref }}$, indicating a high VSWR condition. Once a high VSWR is detected, the input of the transmitter is cut off to protect the amplifiers. 


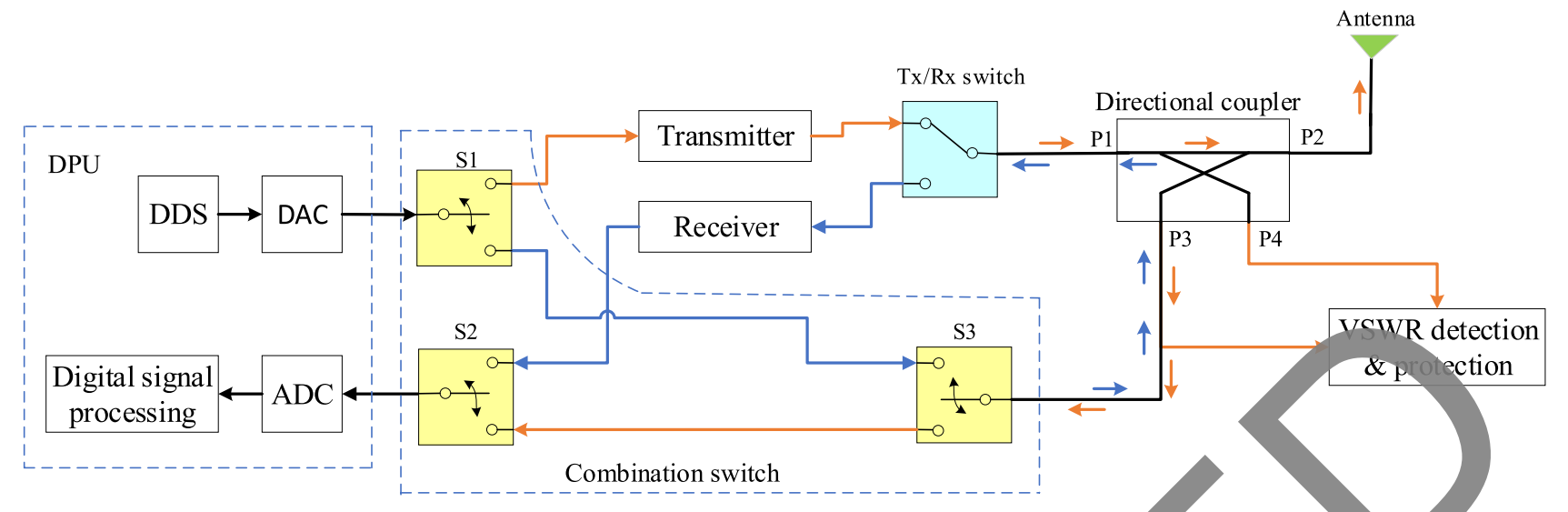

Figure 3. Block diagram of the calibration circuit. The signal paths of the transmitter and receiver cal ation are presented as ange and blue, respectively.

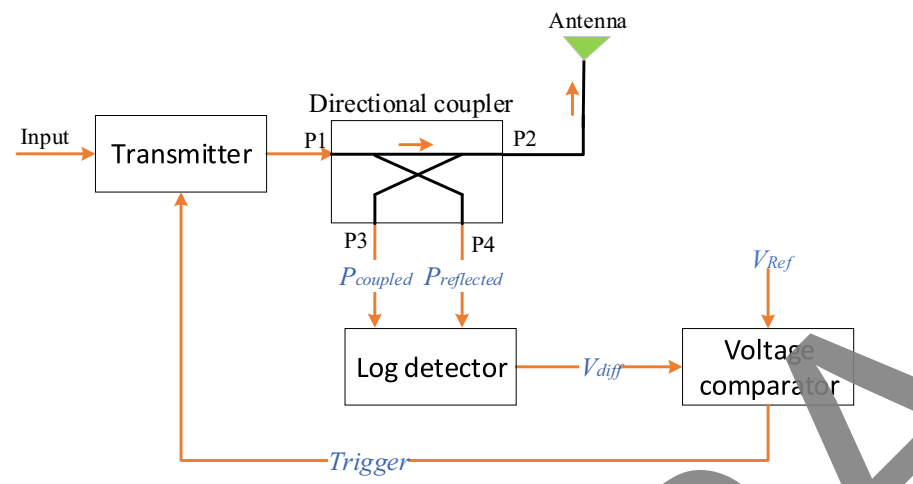

Figure 4. The signal flow diagram of the VS $R$ detecion and protection circuit.

\section{Advanced signal proce sing tec niques}

The AgileDARN radar is cesigned a SuperDARN radar. It can operate as the stand SuperDAR radar, outputting the returns after beam for ng. Besides, the radal is a distributed system, and the DP is an FPC -based reconfigurable module. It can operate as mult e-input-multiple-output (MIMO) radar. The twenty sepate receiver are allowed each to be recorded and stored independenty, which enables postprocessing beam forming, chn imbalance detection, and correction on computer.

\subsection{Calib on of channel imbalance}

Digital beam forming will work correctly, provided that a plane wave incident on the array remains plane following digitization. Implementation departure from an ideal design means that the plane wave requirement will not be achieved exactly and will degrade beam forming performance. The imbalance between channels is an important contributor to the imperfection (Frazer \& Abramovich, 2002). Besides, at high frequency, diffraction during ionospheric propagation will cause wavefront distortion (Theurer \& Bristow, 2015).

In the Tiger- 3 radar, each transceiver utilizes two additional 14-bit ADCs alongside the main receiver 16-bit ADC to measure the $\mathrm{p}^{\mathrm{h}}$ variabilities etwe transceivers (Custovic et al., 2012 Experimental results indicate the worst phase calibration accuracy of the order of $0.153^{\circ}$ at $14 \mathrm{MHz}$ (Nguyen al., 2013). Theurer \& Bristow (2015) presented a scintination correction alge $\mathrm{hm}$ based on adaptive optics techni ues to reduce the diffraction during ionospheric propagation. $N$ ny methods re presented to estimate the effective time de la caused by the difference in the electrical path length that connects the primary array and the interferometric array to the correlator (Chisham \& Freeman, 2013; Ponomarenko et al., 15: Burrell et al., 2016; Chisham, 2018).

In this paper, internal calibration and external calibration are presented to reduce the channel imbalance from antennas (including cables), transmitters, and receivers. The internal calibration is used to remove the amplitude and phase imbalance between transmitters/receivers. The phase imbalance between antennas (including cables) can be reduced by the external calibration.

\subsubsection{Internal calibration}

The internal calibration is implemented based on the calibration circuit presented in Figure 3. The transmitter calibration and receiver calibration are performed, respectively, but in the same way.

During transmitter/receiver calibration, the reference signal is generated in the DPU and delivered to transmitters/receivers. After traveling through the modules, the signals are sampled, processed, and packed in the DPU, respectively. Then, the radar control software picks up the data to detect the imbalance between channels as follows.

Supposed the reference signal is $A_{0} \mathrm{e}^{-j 2 \pi f_{0} t+j \varphi_{0}}$, and the transfer function of the $n$th channel, $H_{n}$, is

$$
H_{n}=g_{n} \mathrm{e}^{j \varphi_{n}} .
$$

Then the signal after the $n$th channel, $v_{n}$, is

$$
v_{n}=A_{0} g_{n} \mathrm{e}^{-j 2 \pi f_{0} t+j\left(\varphi_{0}+\varphi_{n}\right)},
$$

where $A_{0}$ and $\varphi_{0}$ denote the amplitude and initial phase of the reference signal, respectively. $f_{0}$ indicates the operating frequency of the radar. $g_{n}$ and $\varphi n$ depict the gain and phase delay 
of the $n$th transmitter/receiver. With the same input signal, the difference between the output signals represents the imbalance.

Given the 1st channel as the reference, the difference between the $n$th Tx/Rx and the 1st Tx/Rx can be obtained by comparing $v_{n}$ with $v_{1}$.

$$
\left\{\begin{array}{l}
\Delta g_{n}=\frac{g_{n}}{g_{1}} \\
\Delta \varphi_{\mathrm{Tx} / \mathrm{Rx}, n}=\varphi_{n}-\varphi_{1}
\end{array}\right.
$$

where $\Delta g_{n}$ and $\Delta \phi_{n}$ are the correction factors for the $n$th $\mathrm{Tx} / \mathrm{Rx}$ that compensate for amplitude and phase imbalance, respectively. Since the imbalances between Tx/Rxs have been detected, the next step is to remove these differences by compensation.

The correction for transmitters is implemented on FPGA and executed in real-time. The transmitter correction factors are distributed to the generators, compensating transmit signals for transmitter imbalances. Assuming that two sinusoid signals with the same frequency and 90-degree out of phase are generated:

$$
\left\{\begin{array}{l}
s_{I, n}(t)=A_{0} \cos \left(2 \pi f_{0} t\right) \\
s_{Q, n}(t)=A_{0} \sin \left(2 \pi f_{0} t\right)
\end{array}\right.
$$

where $f_{0}$ is the operating frequency, and $A_{0}$ is the amplitude of the transmit signal. $\mathrm{s}_{I, n}(t)$ and $s_{Q, n}(t)$ are the real and imaginary part of the complex transmit signal, $s_{n}(t)$, DBF.

$$
s_{n}(t)=s_{I, n}(t)+j s_{Q, n}(t)=A_{0} \mathrm{e}^{j 2 \pi f_{0} t}
$$

The transmit signal after correction is expresed as

$$
\begin{aligned}
s_{n}^{c}(t)= & \frac{A_{0}}{\Delta g_{n}} \cos \left(2 \pi f_{0} t-\Delta \rho_{\mathrm{Tx}, n}\right) \\
& \times \sin \left(2 \pi f_{0} t\right.
\end{aligned}
$$

The receiver imbalances corrected in same way as the transmitter imbalance whereas the signals compensated are echoes. The correction proces can be executed in real-time (based on FPGA) or pst-processed on computer.

Figure 5 - shows the mbalance between the transmitters before (to and ter (bot m) ibration. The data are measured c unuousl in $24 \mathrm{~h}$. The mplitude and phase differences betwe 16 tran mitters before calibration are $\sim 1 \mathrm{~dB}$ and $\sim 35^{\circ}$, respectively ster calioration, the imbalances are reduced considerably to $\sim 0.03 \mathrm{~dB}$ and $\sim 0.1^{\circ}$. That means the transmit pattern after cabration will be almost the desired pattern (Nguyen et al., 213). Additionally, there are tiny fluctuations caused by external interference.

Figure 6 shows the receiver imbalance before (top) and after (bottom) calibration during the same observation interval depicted in Figure 5. The amplitude and phase differences before calibration are $\sim 1.5 \mathrm{~dB}$ and $\sim 100^{\circ}$, which results primarily from the difference between electronic components. After calibration, the imbalances are reduced significantly to $0.2 \mathrm{~dB}$ and $1^{\circ}$. The receiver noise and external interference bring in fluctuation that cannot be removed by calibration. The noise/interference has a greater impact on receiver calibration than transmitter calibration. The reasons are shown as follows.

Given the external interference is $\epsilon(t)$, the coupling factor of the directional coupler $k_{\mathrm{C}}$, the calibration signal is $v_{0}(t)$, the gains of a transmitter and a receiver are $G_{\mathrm{Tx}}$ and $G_{\mathrm{Rx}}$, respectively. During transmitter calibration, the signal sent to ADC, $v_{\text {Tx,cal }}(\mathrm{t})$, is

$$
v_{\mathrm{Tx}, \mathrm{cal}}(t)=k_{C}\left[G_{T x} v_{0}(t)+\epsilon(t)\right]
$$

and the SNR of $v_{\mathrm{Tx}, \mathrm{cal}}(t)$ is

$$
v_{\mathrm{Tx}, \mathrm{cal}}(t) \text { is }
$$

(G)

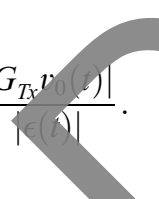

During receiver calibration signal sent $\mathrm{ADC}$ Rx,cal $(t)$, is

$$
v_{\mathrm{Rx}, \mathrm{cal}}(t)=G_{\mathrm{Rx}}\left[k \sigma_{0}(t)+\epsilon(t)\right]
$$

and the SNR of $y$, cal $(t)$

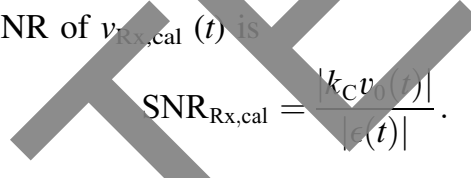

In g neral, $G_{\mathrm{Tx}} \gg 1$ and $k_{\mathrm{c}}<1$. From equations (8) to (10), we can find that the impact of the interference, $\epsilon(t)$, on $\operatorname{SNR}_{\mathrm{Tx}, \mathrm{cal}}$ is far less than on $N R_{R x, c a l}$.

\section{1. External calibration}

The channel imbalance is induced mainly by the antennas (incluaing cables) and transceivers. The imbalance from transceivers can be removed by internal calibration. That from antennas should be detected and corrected by external calibration.

The primary array of the AgileDARN radar is composed of 16 TTFD antennas mounted on poles $9.16 \mathrm{~m}$ off the ground. The size of the array is about $200 \mathrm{~m}$. For a physically large array, phase correction is often accomplished through a landbased or ship-based transponder. In this case, the transponder used as the calibration device must be in the far-field of the array and located in the one-hop ionospheric propagation footprint of the transmitter (Frazer et al., 2009). The one-hop distance depends on the incident angle and the height of the F2 layer (Budden, 1985). Since the SuperDARN radars have broad $\left(\sim 35^{\circ}\right)$ beamwidth in elevation (Greenwald et al., 1985 ), the distance distributes within the range from several hundred kilometers to about $2000 \mathrm{~km}$ (Oinats et al., 2015; Greenwald et al., 2017), which varies with the time of day and season. For the variation of the one-hop distance, it is difficult and costly to perform external calibration by a transponder frequently. Fortunately, there are dispersive targets in nature, such as meteors, that can be used as calibration sources. Solomon et al. (1998) proposed the Weiss-Friedlander MUSIC-type approach for estimating sensor positions and mutual coupling by echoes from meteor trails.

The echoes from meteor trails can be routinely observed by the SuperDARN radars on most days (Hall et al., 1997). The meteor trails are dispersive, and most of them emerge in the slant range less than $500 \mathrm{~km}$. The signal propagation between the radar and the target can be assumed straight-line. Thus, the echoes can be used to calibrate the phase offset between two arrays of a SuperDARN radar (Chisham, 2018). 

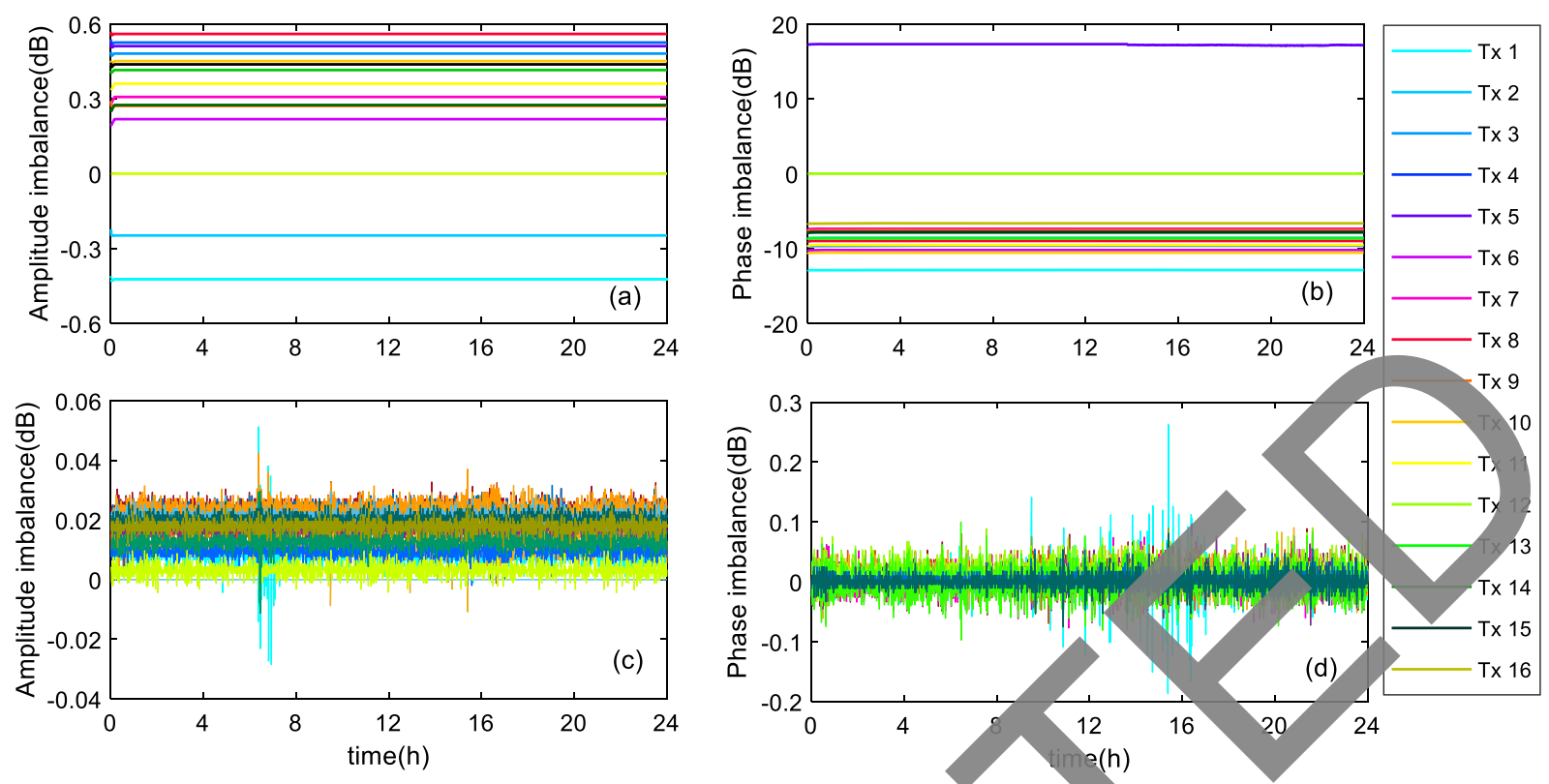

Figure 5. Imbalances between transmitters before (top) and after (bottom) calibration. The data measured continuously in 24 h. (a) The amplitude imbalance before correction. (b) The phase imbalance before correction. (c) The amplitude balance after correction. (d) The phase imbalance after correction.
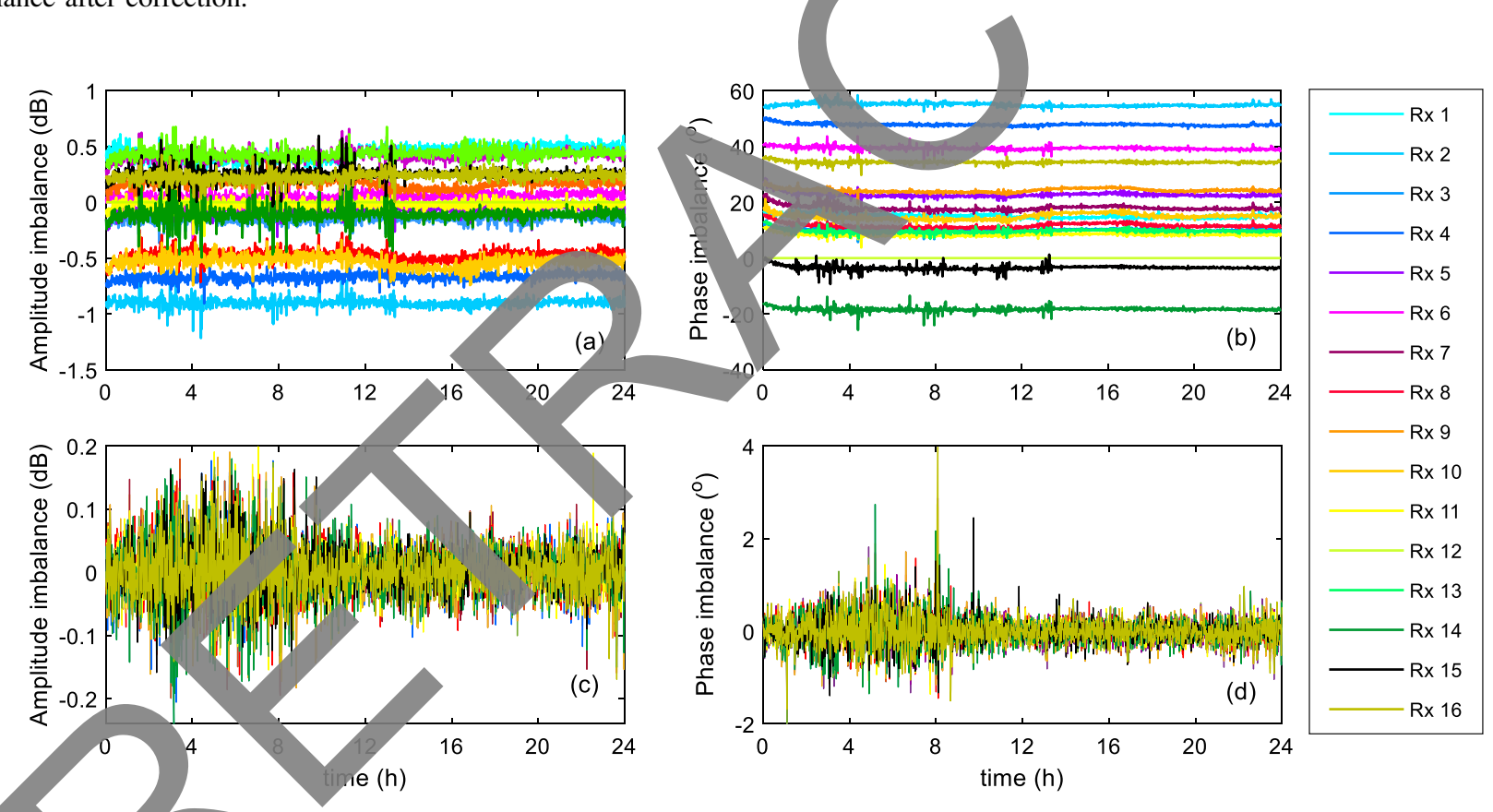

Figure 6. Rece ivere before (top) and after (bottom) calibration during the same observation interval depicted in Figure 5. (a) The amplitude ance before correction. (b) The phase imbalance before correction. (c) The amplitude imbalance after correction. (d) The phase imbalance anter correction.

The backscatter from meteor trails is, in general, featured with planar wavefronts, high signal-to-noise ratio (SNR), adequate duration for sufficient snapshots, and the ability to be received in large numbers over the entire HF band (Solomon et al., 1998). Therefore, the meteor trail can be considered as a point scatter and used to calibrate the channel imbalance of the AgileDARN radar frequently.

The arrays in AgileDARN are uniform linear arrays. If a plane wave incidents upon an array, the phase at each antenna element depends on the angle of arrival of the wave. Given an array of $N$ elements, the phase obtained by the $n$th antenna is $\alpha_{A, n}(n=1,2, \ldots, N)$. The relationship between $\alpha_{A, n}$ and $\alpha_{A, 1}$ is (Zhang, 2009)

$$
a_{A, n}=a_{A, 1}+(n-1) k d \sin \theta_{B}
$$

where $k=2 \pi / \lambda, \lambda$ is the operating wavelength. $d$ denote wave number and the spacing between antenna elements. $\theta_{B}$ indicates the angle of arrival of the wave. The phases of the 
antennas increase or decrease linearly, which is determined by $\theta_{B}$. When the channel imbalance exists, the linearity will be destroyed. The deviations from linear indicate the imbalance.

During external calibration, internal calibration is performed in real-time to remove the imbalance between transceivers. The process steps for external calibration are shown as follows:

1. Pick up meteor echoes based on some currently recognized characteristics of SuperDARN meteor echoes, such as slant range, SNR, line-of-sight (LOS) Doppler velocity, spectral width, and altitude (elevation angle) (Solomon et al., 1998).

2. Further, calculate the phases of echoes received by the antenna elements. The least-squares linear fitting method is used to fit a linear model to the unwrapped phase.

3. The slope of the fit line represents in equation (11). The deviations from the line denote the antenna (including cable) imbalance, $\Delta \alpha_{A, n}$.

4. The correction factors for transmitting channel (including antenna, cable, and transmitter) and receiving channel (including antenna, cable, and receiver) are expressed as

$$
\left\{\begin{array}{l}
\Delta \phi_{T, n}=\Delta \varphi_{\mathrm{Tx}, n}+\Delta \alpha_{A, n} \\
\Delta \phi_{R, n}=\Delta \varphi_{\mathrm{Rx}, n}+\Delta \alpha_{A, n}
\end{array}\right.
$$

where the subscript $n$ denotes the channel index. $\Delta \phi_{T}$ and $\Delta \phi_{R}$ depict the correction factor for transmitting cha and receiving channel, respectively.

5. The last step is to correct the imbalance. The anten imbalances are corrected in the same way as the Tx/R imbalances. The transmitting correction actors are used to compensate the transmit signals and the ceiving correction factors are used to compensate the

As the steps introduced abo more than 30 meteor trails are picked up to get the correction factor of antennas, Figure 7 shows the phase correction factors o the ntennas in the main array. The phase imbalnce is between $-10^{\circ}$ and $11^{\circ}$.

Further, pick up another set of meteor trais and correct the antenna imbalance the cor ction factors. Figure 8 shows the phases of the echoes receiv by 16 receivers before correction. Figure 8 a shows the unw apped phases of the 16 channels and the fitted raigh ines. The valions of the phase have an approx ately lin $r$ character 1 th a deviation between $-15^{\circ}$ and 20 (shown in Fig \&b). The means of the deviation from the fitting line distribute between $-10^{\circ}$ and $10^{\circ}$, with a standard deviation (STD) of $\sim 3^{\circ}$.

After phase correction, the unwrapped phases are re-fitted (shown in Fig. 9.). Most of the deviations distribute between $-10^{\circ}$ and $10^{\circ}$ (shown in Fig. 9b). The means (red circles) are reduced significantly to $\pm 1^{\circ}$, with the same STD. That is because the correction factors are fixed in a calibration interval. The deviation caused by the variation of antennas can be resolved by shortening the calibration interval. In practice, most of the residual errors are caused by the clutter from sidelobes or radio frequency interference (RFI) that cannot be removed by calibration.

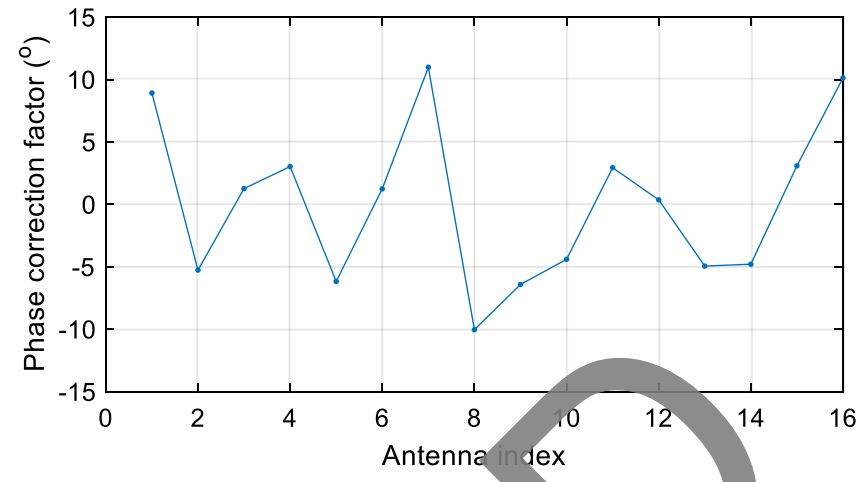

Figure 7. Phase correction factor of the antennas in the main array.

\subsection{Flexible receive am pattorn synthesis}

As a new gen ation Super ARN rad, DBF is adopted to replace a phasing matrix to acom ish beam steering and switching (S alm al., 2004; Heley et al., 2006; Bristow, 2019; Kennedy, 201. There are two ways in AgileDAN to accomplish DBF. Transmitting DBF in the generator is implemented based on FPGA. Digital multiple sub-beam forming fo receiving can select to be implemented on FPGA or comp er (Deng et al. 2019). When AgileDARN operates as a standard SuperDARN radar, it scans 24 directions with a beamwidh $f 3.25^{\circ}$ cho signals are processed by seven sub-beam forming on FA (shown as Fig. 10). It needs to mention that when executing seven sub-beam forming, the same set of data a usec to synthesized to seven different directions. The 4th sub-beam is steered towards the boresight of transmitting beam. The sub-beam number is fixed and limited by the resource of FPGA. When the radar operates as a MIMO system, the twenty separate receivers are recorded and stored independently. Multiple sub-beam forming is off-line processing on computer and the sub-beam number can set as needed.

The typical SuperDARN radars scan16-24 directions over a field of view of $\sim 52^{\circ}-78^{\circ}$ in azimuth, with a beamwidth of $\sim 3.24^{\circ}$ (Greenwald et al., 1985). The AgileDARN radar scans 24 directions with a beamwidth of $3.25^{\circ}$. By $M$ sub-beam forming, the angular separation of receiving is decreased to $3.25^{\circ} \mathrm{M}$. For the typical beam forming, the direction of arrival (DOA) is considered as the boresight. The maximum position error is up to $1.625^{\circ}$. By $M$-beam forming, a beam is split into $M$ sub-beams. The power distribution in the beam is obtained to estimate the DOA. In general, the direction with the strongest echo is considered as the DOA with a maximum error of $1.625 \%$. The position accuracy is improved by $M$ times, which means the position accuracy is proportional to $M$. However, the accuracy is limited by the sensitivity of the radar system. When the sub-beam is too narrow, the difference between sub-beams cannot be distinguished. The position accuracy cannot be improved any more.

Figure 11 shows the power distribution in FOV with a separation of $0.464^{\circ}$ (seven sub-beam forming) and $3.25^{\circ}$ (typical beam forming). During transmitting, array scans 24 directions with a beamwidth of $3.25^{\circ}$. The dwell time on each beam is $\sim 2.3 \mathrm{~s}$ (integration period). For each integration period, 26 seven-pulse sequences are transmitted, then 26 sets of lag 

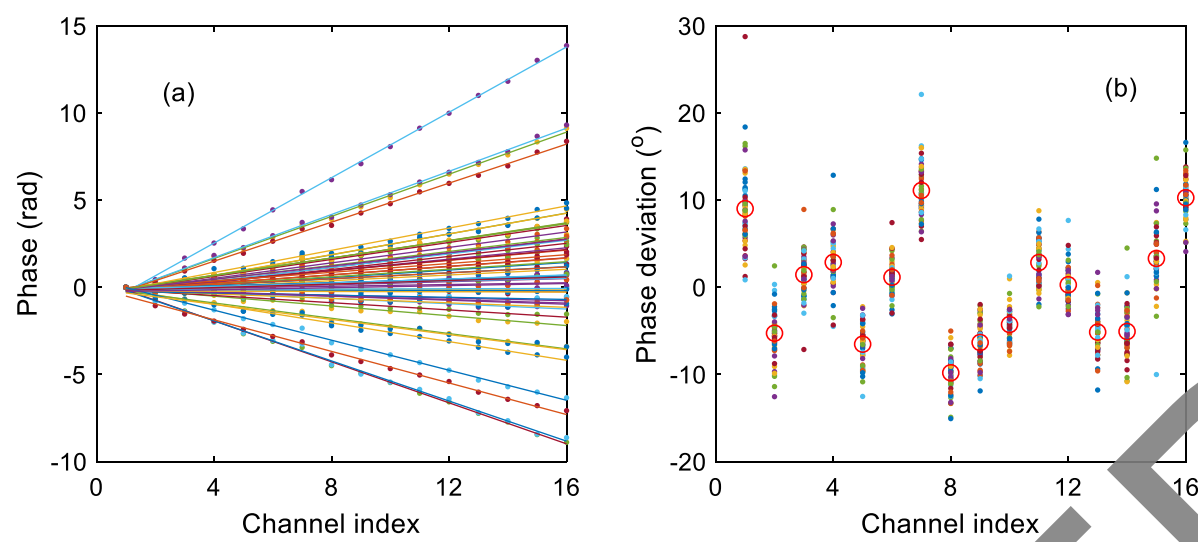

Figure 8. Phases of the echoes from meteor trails received by 16 receivers before correction. (a) The un apped phases the 16 hannels and the fitted straight lines. The dots with different colors denote different sets of phases of the 16 channel The lines th different colors represent different fitted straight lines. (b) The phase deviation from the fitted lines. The dots with different coldenot de deviation between measured phases from different meteors and the fitted phases. The means of the deviations are presented red ches. 1 he mean se between $-10^{\circ}$ and $10^{\circ}$, with a standard deviation (STD) of $\sim 3^{\circ}$.

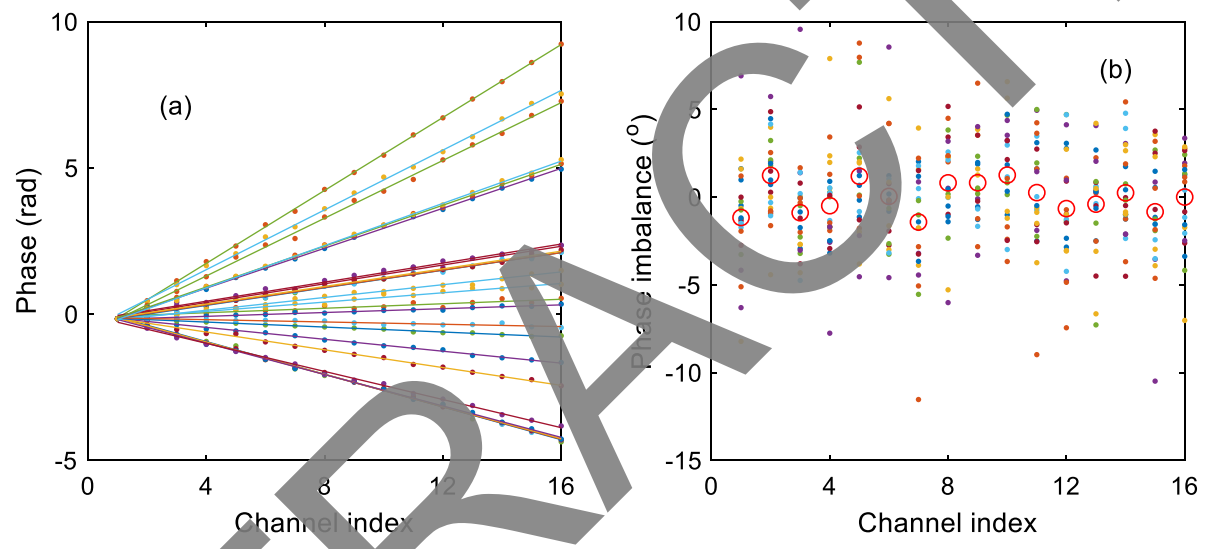

Figure 9. Phases of the echoes from neteor trails received by 16 receivers after correction. (a) The unwrapped phases of the 16 channels after correction and the re-fitted straight The dots with ifferent colors denote different sets of phases after correction of the 16 channels. The lines with different colors repre diterent re-fitted stight lines. (b) The phase deviation from the re-fitted lines. The dots with different colors denote the deviation between corrected phases from different meteors and the re-fitted phases. The means of the deviations after correction are presented as red circles. Compang to Figure 8, the means after correction are reduced significantly to $\pm 1^{\circ}$, with the same STD.

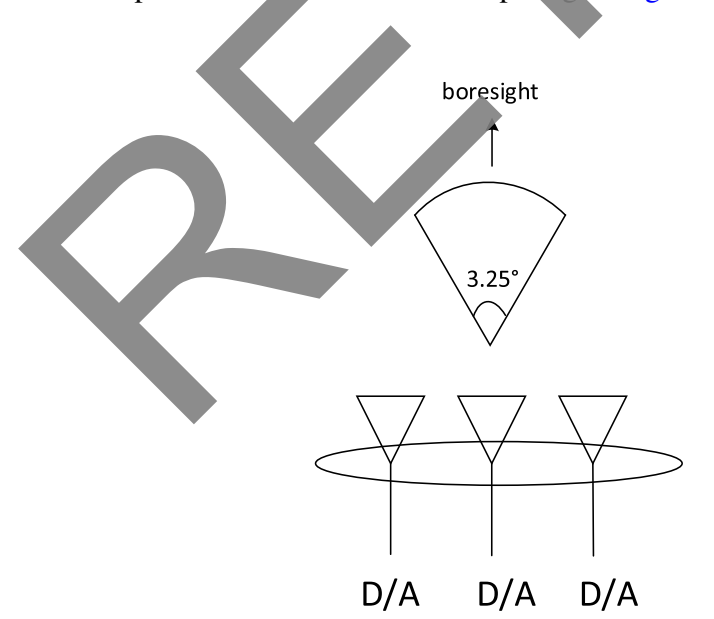

(a) Typical DBF for transmitting

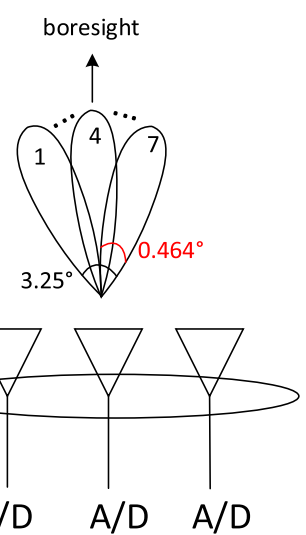

(b) Seven sub-beam forming for receiving

Figure 10. Schematic diagram of beam forming for transmitting and receiving in the AgileDARN radar. (a) Typical DBF for transmitting with a beamwidth of $3.25^{\circ}$. (b) Seven sub-beam forming for receiving to separate $3.25^{\circ}$ into seven sub-beams of $0.464^{\circ}$. 

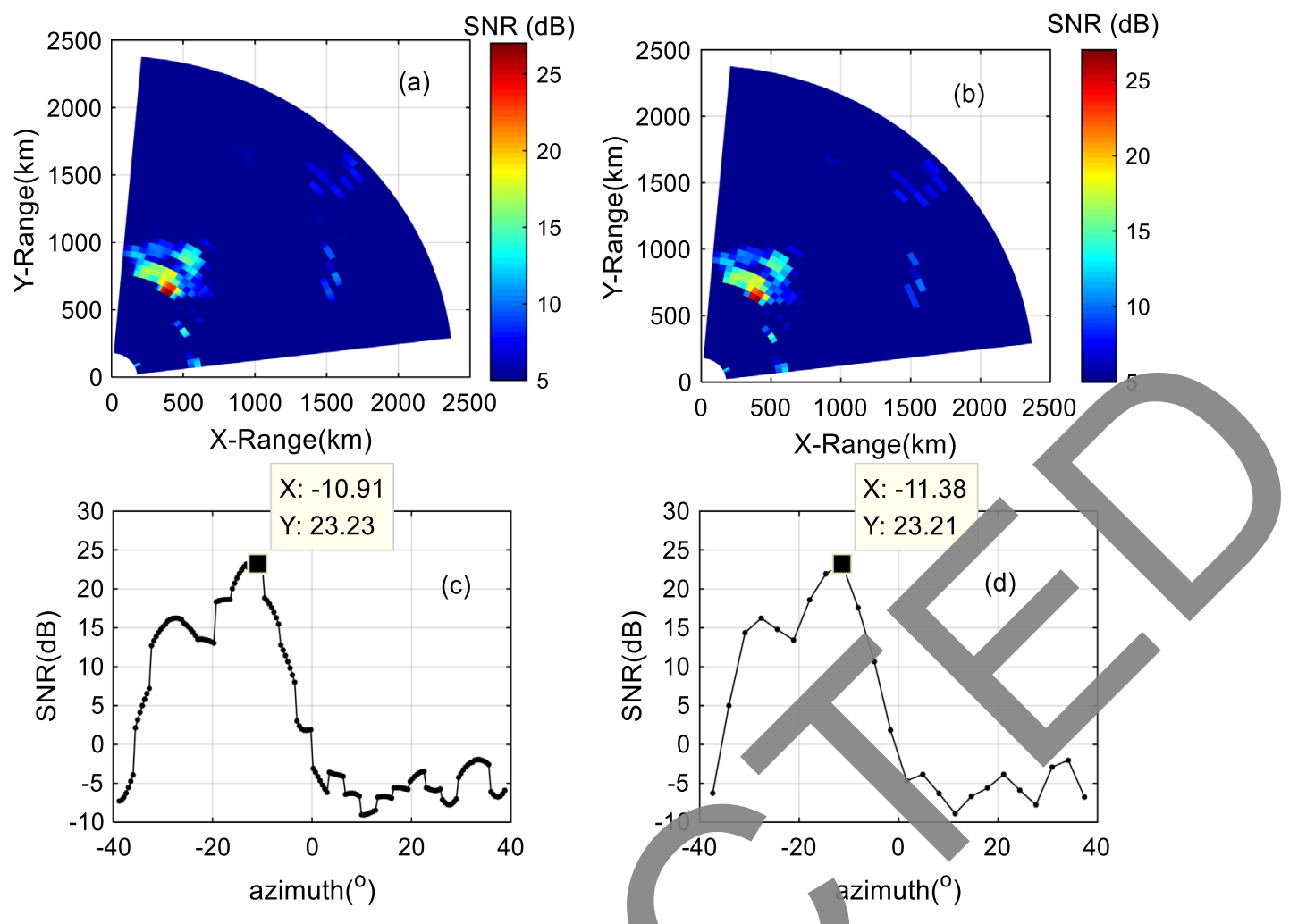

Figure 11. Power distribution in FOV. (a) Power distribution in FOV wit the angular se ration of $0.464^{\circ}$ (seven sub-beam forming). (b) Power distribution in FOV with the angular separation of $3.25^{\circ}$ (typical beam forning). (c) $\mathrm{P}$ wer distribution in the range of $855 \mathrm{~km}$ varying in azimuthal with a separation of $0.464^{\circ}$. (d) Power distribution

ith a zero power for all ranges (from $180 \mathrm{~km}$ to $2430 \mathrm{~km}$ with a
interval of $45 \mathrm{~km}$ ) are averaged to improve $\mathrm{SNR}$ Ribeiro et al., 2013). Figures $11 \mathrm{a}$ and $11 \mathrm{~b}$ exhibit the power dibution in FOV with a separation of $0.464^{\circ}$ and $325^{\circ}$,

There are strong echoes appear in rang $\sim 855 \mathrm{~km}$ in the two pictures, whereas the diffe ce cannot be listinguished easily by naked eye. Figures $\mathrm{ic}$ and $11 \mathrm{~d}$ show the power distribution of the echoes from $855 \mathrm{~km}$ in azimuth. The peaks occur at $-10.91^{\circ}$ in (c) 2 in $-11.38^{\circ}$ in (c), with a difference of $0.47^{\circ}$. That means th the position accura has an improvement of $0.47^{\circ}$ by sever sub-bean forming. However, the echoes of the seven sub-beams are nthesized by the same data set rather than by seven indendent data sets. Consequently, the power distribution in (c) aries discontinuously with azimuth.

Addi nally, quencies from 8 to $20 \mathrm{MHz}$ are a portion of the radio band th the radio waves are bent by the ionosphere so that the wa tes return to the Earth's surface at long distances beyond the orizon. Thus HF over-the-horizon (OTH) radars are designea detect not only ionospheric irregularities but also aircraft, ship, and weather effects over the ocean (Skolnik, 2003). The conventional beamformers are susceptible to interference signals. The signals from other OTH radars may contaminate the returns of SuperDARN radars when they occur at sidelobes of the array. By contrast, adaptive, or statistically optimum, beamformers can account for interference signals. An adaptive beamformer algorithm chooses the weights based on the statistics of the received data. For example, an adaptive beamformer can improve the SNR by using the received data to place nulls in the array response. These nulls are placed at angles corresponding to the interference signals. As multiple sub-beam forming, adaptive beam forming can be implemented on FPGA or computer, it is more flexible on computer. The adaptive methods can be selected for different requirements.

\section{Summary and conclusion}

The AgileDARN radar is the first mid-latitude SuperDARN radar in China. The geographic coordinates of the radar site are $46.8^{\circ} \mathrm{N}, 130.5^{\circ} \mathrm{E}$. It looks to the northeast with a boresight azimuth of $44^{\circ}$ in geographic coordinates and has a common viewing area with the Hokkaido pair of radars (HOK and HKW). The AgileDARN radar can be validated by comparing its observations with those from the Hokkaido radars.

The radar has an FPGA-based DPU to implement digital signal processing, such as DBF. Besides, it can provide distributed signal processing as a MIMO radar. The 20 separate receivers are allowed each to be recorded and stored independently. The receive beam forming, the detection of the channel imbalance, and the correction of the receiving channel imbalance are post-processed on computer with flexibility. Multiple sub-beam forming is implemented to improve the position accuracy.

The imbalance between channels can degrade beam forming performance. Internal calibration and external calibration are proposed to reduce the imbalance from transmitters, receivers, and antennas. The calibration circuits are designed to accomplish the transmitter and receiver calibration individually. The reference signals for calibration are generated by the generators 
in the DPU. The internal calibration is executed with an interval of $1 \mathrm{~min}$. By the internal calibration, the imbalances between transmitters/receivers are eliminated significantly. During the external calibration, the echoes from meteor trails are used as calibration signals to detect the imbalance between antennas. The calibration interval is determined by the stability of the antenna imbalance. In a calibration interval, the imbalances between antennas are expected to remain stable. Fortunately, meteors can be routinely observed by the HF radar on most days, but the detecting ability of meteors depends dominantly on transmit power, operating frequency, and range resolution. With the same transmit power and operating frequency, a higher range resolution can detect more meteors. The calibration can reduce effectively the imbalance between channels but has no effect on the fluctuation caused by clutter or radio frequency interference (RFI).

Acknowledgements. The authors would like to thank J.M. Rouhoniemi, K.T. Sterne, N. Nishitani, P.V. Ponomarenko, and A. S. Yukimatu for their insightful comments about the design and data processing of the AgileDARN radar. We also thank the SuperDARN community for the open nature of the technical exchange of information. This work was supported by the National Natural Science Foundation of China (Grant No.: 42004139), the Frontier Science Key Research Project of Chinese Academy of Sciences (Grant No.: QYZDY-SSWJSC014), and the Large Research Infrastructures-Groundbased Space Environment Monitoring Network. The AgileDARN data are available from the BAS SuperD $\mathrm{RN}$ data mirror website. (http://vt.superdarn.org/tiki-index.p ? page=Data+Access or https://www.bas.ac.uk/project/superdar \#data). The editor thanks Michael Kosch and an anymou reviewer for their assistance in evaluating this paper.

\section{References}

Baker JBH, Greenwald RA, Rưononiemi M Oksavik K, Gjerloev JW, Paxton LJ, Hairston MR. 2007. Obse tions of ionospheric convection from the Wallops SuperDAR radar at middle latitudes: OBSERY IIONS PROM THE WALLOPS RADAR. $J$ Geophys Res Space Ph 112(A1): A01303. https://doi.org/ 10.1029/2006JA011

Bristow WA 2019 Appliction of ADAR imaging analysis to SuperD RN observations. Radi ci 54, 692-703. https://doi.org/ 10.1 9/2019RS 06851.

Budde KG. 1985. The propagation of radio waves: The theory of radio wat of low power in the ionosphere and magnetosphere (1st Ed.). ambridge University Press. https://doi.org/10.1017/ CBO978051 564321.

Burrell AG, Yeoma TK, Milan SE, Lester M. 2016. Phase calibration of interferometer arrays at high-frequency radars. Radio Sci 51(9): 1445-1456. https://doi.org/10.1002/2016RS006089.

Chisham G. 2018. Calibrating SuperDARN interferometers using meteor backscatter. Radio Sci 53(6): 761-774. https://doi.org/ 10.1029/2017RS006492.

Chisham G, Freeman MP. 2013. A reassessment of SuperDARN meteor echoes from the upper mesosphere and lower thermosphere. J Atmos Sol Terr Phys 102: 207-221. https://doi.org/ 10.1016/j.jastp.2013.05.018.
Chisham G, Lester M, Milan SE, Freeman MP, Bristow WA, Grocott A, et al. 2007. A decade of the Super Dual Auroral Radar Network (SuperDARN): Scientific achievements, new techniques and future directions. Surv Geophys 28(1): 33-109. https://doi.org/ 10.1007/s10712-007-9017-8.

Custovic E, McDonald A, Kane T, Vu V, Whittington J, Devlin J. 2012. Next generation of over the horizon HF Radars and the determination of foF2 in real-time. In: Proceedings of the 11th Australian Space Science Conference, National Space Society of Australia Ltd, pp. 141-156. ISBN: 978-0-9775740-5-6.

Deng X, Yan J, Wu J, Lan A. 2019. A Method and implementation of internal calibration in AgileDARN $\mathrm{AF}$ Radar. Remote Sens Technol Appl 34(6): 1221-122 http://www.rs ac.cn/CN/ 10.11873/j.issn.1004-0323.2019,6.122

Frazer GJ, Abramovich YI, John n BA. 2009 MIMO b ed spatial calibration of OTHR transnit arrays. In: 2009 Internatonal Radar Conference "Surveillan for a S r World" (ADAR 2009), Bordeaux, France, pp. ISBN 78-2-912328-55-7.

Frazer GJ, Abramovi YI. 2002 aantifying malti-channel receiver calibration. In: Asor Array d Multichnel Signal Processing Workshop P ocedings, Rosslyy USA, pp. 561-564. https://doi. org/10.11 SAM 2002.1191103.

Greenwald RA, Weiss Nielsen E, Thomson NR. 1978. STARE: A new ralar auroral back catter experiment in northern Scandinavia. Radio Sci 13(6)./1021-1039. https://doi.org/10.1029/ S013i006p01021.

Greenwald RA, Baker KB, Hutchins RA, Hanuise C. 1985. An HF phased-array rad for studying small-scale structure in the highlatitude ionosphere. Radio Sci 20(1): 63-79. https://doi.org/ 10.1029/RS020i001p00063.

Treenwald RA, Baker KB, Dudeney JR, Pinnock M, Jones TB, Themal, et al. 1995. DARN/SuperDARN: A global view of the dynamics of high-latitude convection. Space Sci Rev 71(1-4): 761-796. https://doi.org/10.1007/BF00751350.

Greenwald RA, Frissell N, de Larquier S. 2017. The importance of elevation angle measurements in $\mathrm{HF}$ radar investigations of the ionosphere. Radio Sci 52(3): 305-320. https://doi.org/10.1002/ 2016RS006186.

Hall GE, MacDougall JW, Moorcroft DR, Maurice J-P, Manson AH, Meek CE. 1997. Super Dual Auroral Radar Network observations of meteor echoes. J Geophys Res Space Phys 102(A7): 1460314614. https://doi.org/10.1029/97JA00517.

Healey RC, Parkinson ML, Devlin JC, Gentile M, Ye H. 2006. Enhanced beam steering capabilities for the TIGER SuperDARN radars. In: Australia Institute of Physics 17th National Congress, Brisbane, pp. 1-4, Paper 125. ISBN: 0-9598064-7-4

Kennedy P. 2019. Design of Software Defined Radio for SuperDARN Radars, MS Thesis, Virginia Tech. https://vtechworks.lib.vt.edu/ bitstream/handle/10919/89908/Kennedy_P_S_T_2019.pdf

Nguyen HQ, Whittington JS, Devlin JC, Vu HL, Vu N-V, Custovic E. 2013. Accurate phase calibration for digital beamforming in multi-transceiver $\mathrm{HF}$ radar system. Int $J$ Electron Telecommun 59(3): 245-254. https://doi.org/10.2478/eletel-20130029.

Nishitani N, Ruohoniemi JM, Lester M, Baker JBH, Koustov AV, Shepherd SG, et al. 2019. Review of the accomplishments of midlatitude Super Dual Auroral Radar Network (SuperDARN) HF radars. Prog Earth Planet Sci 6(1): 27. https://doi.org/10.1186/ s40645-019-0270-5.

Oinats AV, Kurkin VI, Nishitani N. 2015. Statistical study of medium-scale traveling ionospheric disturbances using SuperDARN Hokkaido ground backscatter data for 2011. Earth Planet Space 67(1): 22. https://doi.org/10.1186/s40623-015-0192-4. 
Parkinson M, Devlin JC, Whittington J. 2006. Why do we need "DIGIDARN" - A global network of digital SuperDARN radars? In: Proceedings of the Workshop on the Applications of Radio Science (WARS) 2006 Conference, Leura, Australia, 2006, Paper R-25, pp. 1-14. ISBN: 0643093184.

Ponomarenko P, Nishitani N, Oinats AV, Tsuya T, Maurice J-P. 2015. Application of ground scatter returns for calibration of $\mathrm{HF}$ interferometry data. Earth Planet Space 67(1): 138. https://doi.org/ 10.1186/s40623-015-0310-3.

Rachakonda A, Hawkins L. 2000. Log amps and directional couplers enable VSWR detection. Retrieved from https://www. analog.com/en/technical-articles/log-amps-and-directional-couplersenable-vswr-detection.html.

Ribeiro AJ, Ruohoniemi JM, Ponomarenko PV, Clausen LBN, Baker JBH, Greenwald RA, et al. 2013. A comparison of SuperDARN ACF fitting methods: SUPERDARN ACF FITTING. Radio Sci 48 (3): 274-282. https://doi.org/10.1002/rds.20031.

Salim T, Devlin J, Whittington J. 2004. FPGA implementation of a phased array DBF using polyphase filters. In: 2004 IEEE International Conference on Field-Programmable Technology (IEEE Cat. No.04EX921), Brisbane, Australia, pp. 339-342.

Skolnik MI. 2003. Introduction to Radar Systems (3rd Ed.), Tata McGraw-Hill Publishing Company Limited, New Delhi. ISBN: 007-044533-8.
Solomon ISD, Gray DA, Abramovich YI, Anderson SJ. 1998. Overthe-horizon radar array calibration using echoes from ionised meteor trails. IEEE Proc Radar Sonar Navig 145(3): 173-179. https://doi.org/10.1049/ip-rsn:19981899.

Sterne KT, Greenwald RA, Baker JBH, Ruohoniemi JM. 2011. Modeling of a twin terminated folded dipole antenna for the Super Dual Auroral Radar Network (SuperDARN). In: 2011 IEEE RadarCon (RADAR), Kansas City, MO, USA, pp. 934-938. https://doi.org/10.1109/RADAR.2011.5960673.

Theurer TE, Bristow WA. 2015. Application of adaptive optics to scintillation correction in phased array hig -frequeney radar. Radio Sci 50(6): 526-538. https://doi.org/10/0/2015R 5703.

Whittington J, Devlin J, Salim T. 2002. Evaluation of digital generation and phasing techniques fo ransmitter sig ls of the TIGER N.Z. Radar. In: P ceedings f the Wo shop on Applications of Radio S nce (WARSO2, Ley Australia, 2002, pp. 1-9. ISBN: 0 80476-0

Zhang GY. 2009. Princip f phas array radar. National Defence Industry Press, Beljing. ISBN $187118065 / 18$.

Zhang JJ, Wang W Wang C, Lan AL, Yar JX, Xiang D, et al. 2020. First observation of ionospherio n ecion from the Jiamusi HF radar during a strong geomagnetic sorm. Earth Space Sci 7(1). https://doi.org/10.1029/2019EA000911.

Cite this article as: Yan J, Lan A, Deng X, Zhang J, Wang C, et al. 202 An agile high- quency radar used for ionospheric research. J. Space Weather Space Clim. 11, 25. https://doi.org/10.1051/swsc/2021010. 